\title{
Understanding sperm motility mechanisms and the implication of sperm surface molecules in promoting motility
}

Srinjoy Chakraborty and Sudipta Saha* (0)

\begin{abstract}
Background: It is estimated that approximately $8-12 \%$ of couples globally face problems associated with infertility. A large number of men exhibit suboptimal sperm parameters. Sperm motility is one of the factors that is measured when analysing sperm parameters. The indication of several crucial sperm surface molecules, having the ability to modulate motility, has opened new avenues in understanding the complex processes involved in motility.

Main body of the abstract: There are various mechanisms that regulate and enhance sperm motility. Several surface molecules on sperm cells can also regulate motility, thus showing their possible application as a treatment for infertility caused by impaired motility. Sperm motility is regulated by intracellular and extracellular $\mathrm{pH}$, along with calcium ions $\left(\mathrm{Ca}^{2+}\right)$ and carbonate ion $\left(\mathrm{HCO}_{3}{ }^{-}\right)$concentrations. Moreover, sperm cells have an array of surface proteins which play a critical role in their function and motility. The indication of surface molecules presented new opportunities for understanding sperm motility and the possibility of treating infertility caused by impaired sperm function. Infertility and problems associated with conception can cause underlying stress and mental trauma. Although there are several methods for treating infertility, most are complex, invasive, and expensive.

Conclusion: It is important to understand how surface molecules and proteins on the sperm cell regulate motility. This will enable us to treat anomalies associated with proper sperm function. This review highlights the general mechanisms that regulate sperm motility, and it stresses the importance and relevance of sperm surface molecules in regulating sperm motility.
\end{abstract}

Keywords: Sperm motility, Membrane proteins, Fertilization, Fertility regulation, Infertility, IVF

\section{Introduction}

Sperm cells are specialized haploid cells that act as the male gamete. During fertilization, sperm cells fuse with the ovum to form a zygote. It is estimated that approximately $8-12 \%$ of couples worldwide are affected by infertility and problems of impaired fecundity. Globally, $40-50 \%$ of the infertility cases are caused by male factor infertility, and as many as $2 \%$ of all men exhibit suboptimal sperm parameters. Semen analysis is routinely used

*Correspondence: ssaha2@amity.edu

Molecular Reproductive Physiology Laboratory, Amity Institute

of Physiology and Allied Sciences, Amity University Uttar Pradesh, Noida

Campus, Sector 125, Noida, Uttar Pradesh 201 303, India to investigate male infertility. Sperm motility is a key factor in determining the quality of semen and a reliable predictor for fertilization success [1]. Male infertility is usually diagnosed on finding abnormal results on semen analysis. Descriptive diagnoses usually include "oligozoospermia" (reduced sperm count), "asthenozoospermia" (reduced sperm motility), and "teratozoospermia" (reduced percentage of sperm with normal morphology). One of the major causes of male infertility is idiopathic primary testicular dysfunction with abnormal spermatogenesis. Other conditions contributing to male infertility are testicular damage due to systemic chemotherapy for cancer, Klinefelter syndrome, genetic mutations, testicular cancer, pelvic irradiation or surgery, trauma, 
cryptorchidism, infection, autoimmune destruction, and drugs [2].

Sperm cells are smaller than most cells in the body; they have a distinctive head, mid-piece, and tail region. Capacitation is an important process that leads to the destabilization of the acrosomal sperm head which allows the sperm to penetrate the ovum. During capacitation, several biochemical changes occur in the tail that enhances sperm motility, and there is a significant amount of efflux of cholesterol in the plasma membrane leading to an increase in membrane fluidity and permeability to bicarbonate and calcium ions, an increase in the polarization of the plasma membrane and changes in protein phosphorylation and protein kinase activity. There is also an increase in the intracellular concentrations of bicarbonate ions $\left(\mathrm{HCO}_{3}{ }^{-}\right)$, calcium ions $\left(\mathrm{Ca}^{2+}\right)$, and cyclic adenosine monophosphate (cAMP) levels [3-5]. Studying sperm morphology and understanding each physiological process is crucial in eliminating various complications that may arise during conception. This narrative review highlights the factors that influence the motility of sperm cells, and it discusses the role of surface molecules present on the surface of the sperm cell that influences motility, and the role of these molecules as potential candidates for treating infertility caused by impaired sperm function.

\section{Asthenozoospermia and its causes}

Asthenozoospermia or asthenospermia is a condition that is characterized by reduced or no motility of sperm cells in the fresh ejaculate. Sperm cells undergo maturation in the epididymis and acquire motility during the epididymal transition [6]. Motility is a very important parameter for successful fertilization. Impaired motility can result in unsuccessful fertilization and can be caused by several reasons which are described in Table 1 .

Sperm cells are transcriptionally and translationally inactive, but there are several specific metabolic pathways that are able to regulate their ability to fertilize an ovum. Sperm motility is also regulated by several signalling cascades and mechanisms. Most notable is the cAMP/protein kinase A and phosphoinositide 3-kinase signalling, which are mediated through $\mathrm{Ca}^{2+}, \mathrm{HCO}_{3}{ }^{-}$, or both [12]. This review describes the relevance of each of the pathways in regulating sperm motility.

\section{Sperm maturation in the epididymis and its role in infertility}

During the early stages of maturation, sperm cells are essentially non-functional, non-motile, and lack the ability to fertilize an egg. Once they transition through the epididymis from the proximal to the distal end, they acquire motility and the ability to fertilize. A significantly higher number of men exhibiting idiopathic infertility suggests maturational disorders. With the advent of assisted reproductive technology, such as intracytoplasmic sperm injection (ICSI), it has become easy to overcome the lack of fertilization caused by idiopathic infertility. However, with the success of ICSI, basic investigation involving epididymal function has reduced considerably. This is a cause for concern because common sense would dictate that most couples try to conceive

Table 1 List of notable causes of male infertility and their relationship with impaired motility

\begin{tabular}{|c|c|}
\hline $\begin{array}{l}\text { Notable causes of } \\
\text { male infertility }\end{array}$ & Relationship with motility \\
\hline Varicocele & $\begin{array}{l}\text { Results in elevated levels of reactive oxygen species (ROS) which alters the testicular microenvironment, thereby causing } \\
\text { reduced motility [7]. } \\
\text { Damaged mitochondria result in abnormal expression of mitochondrial proteins, thereby decreasing ATP levels and altering } \\
\text { calcium signalling cascade [8]. }\end{array}$ \\
\hline Genetic abnormalities & $\begin{array}{l}\text { Defect in several genes coding for the proteins in the central axoneme apparatus, dynein proteins, as well as genes such as } \\
\text { Spag } 6,16,17 \text { that are responsible for central axoneme function result in impaired motility [9-11]. }\end{array}$ \\
\hline Lifestyle choices & $\begin{array}{l}\text { Lifestyle factors such as smoking, stress, and alcoholism may affect sperm parameters. Tobacco smoke containing traces of tar, } \\
\text { carbon monoxide, polycyclic aromatic hydrocarbons, and heavy metals are known to influence motility [12]. }\end{array}$ \\
\hline Radiation & $\begin{array}{l}\text { Causes genetic abnormalities and production of ROS. Catsper genes are known to be mutated due to exposure to radiation, } \\
\text { thereby causing impaired calcium metabolism [13]. }\end{array}$ \\
\hline Heat exposure & $\begin{array}{l}\text { Heat exposure downregulates mitochondrial activity and decreases ATP levels. Heat exposure also decreases antioxidant } \\
\text { levels, alters protein expression, and causes mitochondrial degeneration [14]. }\end{array}$ \\
\hline Environmental Factors & $\begin{array}{l}\text { Environmental chemicals, such as pesticides, polychlorinated biphenyls, bisphenol A, glycol ethers, perfluoronated com- } \\
\text { pounds, dioxins and dioxin-like compounds, phthalates, heavy metals, dichloro-diphenyl-trichloroethane, and plasticizers are } \\
\text { known to affect sperm motility [12]. }\end{array}$ \\
\hline Infections & $\begin{array}{l}\text { Bacterial infections, leucocyte accumulation (leukocytospermia), antibody buildup, inflammation and oxidative stress are } \\
\text { known to impair fertility. Infections reduce mitochondrial membrane potential and increases apoptosis [15]. }\end{array}$ \\
\hline Psychological stress & $\begin{array}{l}\text { Hormones such as corticosterone suppress testosterone and inhibin, thereby altering the testicular microenvironment. Hor- } \\
\text { monal changes are known to affect motility [12]. }\end{array}$ \\
\hline
\end{tabular}


using much less invasive methods. Therefore, it is important to elucidate the process of sperm maturation and maturational changes that spermatozoa undergo during epidydimal transit [16].

The epididymis is grossly divided into three regions: the caput (head), corpus (body), and cauda (tail). Each region of the epididymis, as described in Fig. 1, performs distinctive functions. The caput contributes to the early maturation events, whereas the corpus participates in late maturation events. The cauda region serves as a reservoir for storing functionally mature cells. The primary cell type along the epididymal tubule remains the same from the proximal to the distal end; however, cells from each region exhibit different subsets of genes, thus contributing to the ever-changing luminal environment [17, 18]. A septum further subdivides the caput, corpus, and cauda epididymis into discrete intraregional segments and that region-specific gene expression may in fact be highly ordered and compartmentalized within these precise segments [18]. Several sperm-associated proteins such as ADAM2 (fertilin $\beta$ ), ADAM3 (cyritestin), ADAM24 (testase), and CE9 are proteolytically cleaved and activated by various proteases during the epididymal transition. Interestingly, several free radical scavenging enzymes such as $\gamma$ glutamyl transpeptidase, glutathione peroxidases, and superoxide dismutase are produced in the epididymis to prevent oxidative damage of the sperm cell membrane in the oxygen-rich epididymal lumen. As the spermatozoa migrate from the proximal to the distal regions of the epididymis, they are exposed to segmentspecific gene expression encoding signalling molecules, regulatory proteins, transporters, and receptors, thus contributing to the formation of a unique microenvironment in each segment [18-20].

\section{Altered structure of the flagellum impairs motility}

The four core elements of the sperm cell are described in Fig. 2. The vigorous beating of the flagella is crucial for penetrating through the corona radiata. It is clear that immotile sperm cannot pass through the cervical mucus. Moreover, the type of movement is also crucial. For example, sperm moving in tight circles cannot travel through the uterotubal tract. Only forward-moving sperm can successfully fertilize the ovum [21]. The flagellum propels the sperm through the cervical mucosa in the female genital tract. It mainly consists of a structure known as the axoneme. This highly conserved microtubule-based structure is very similar to the internal cytoskeleton of motile cilia that are found at the surface of many cell types such as the epithelial cells from the airways, the fallopian tubes, or the brain ventricles.

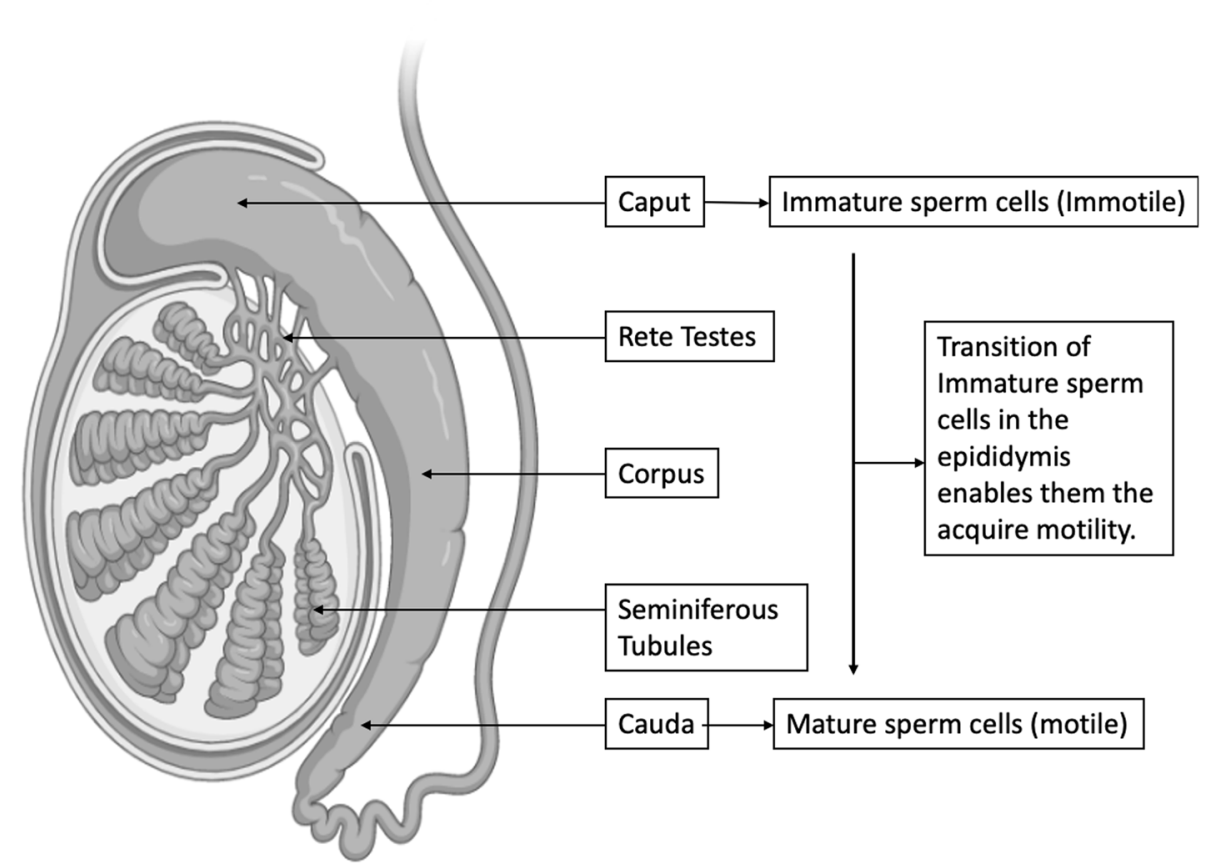

Fig. 1 Diagram of the epididymis. The epididymis is comprised of four anatomical regions: the initial segment, caput, corpus, and cauda. Alterations in membrane composition are driven by concentration gradients of specific enzymes and molecules along the tubule lumen. Sperm maturation occurs during epididymal transit by the interaction of sperm cells with the unique luminal environment of each epididymal region 


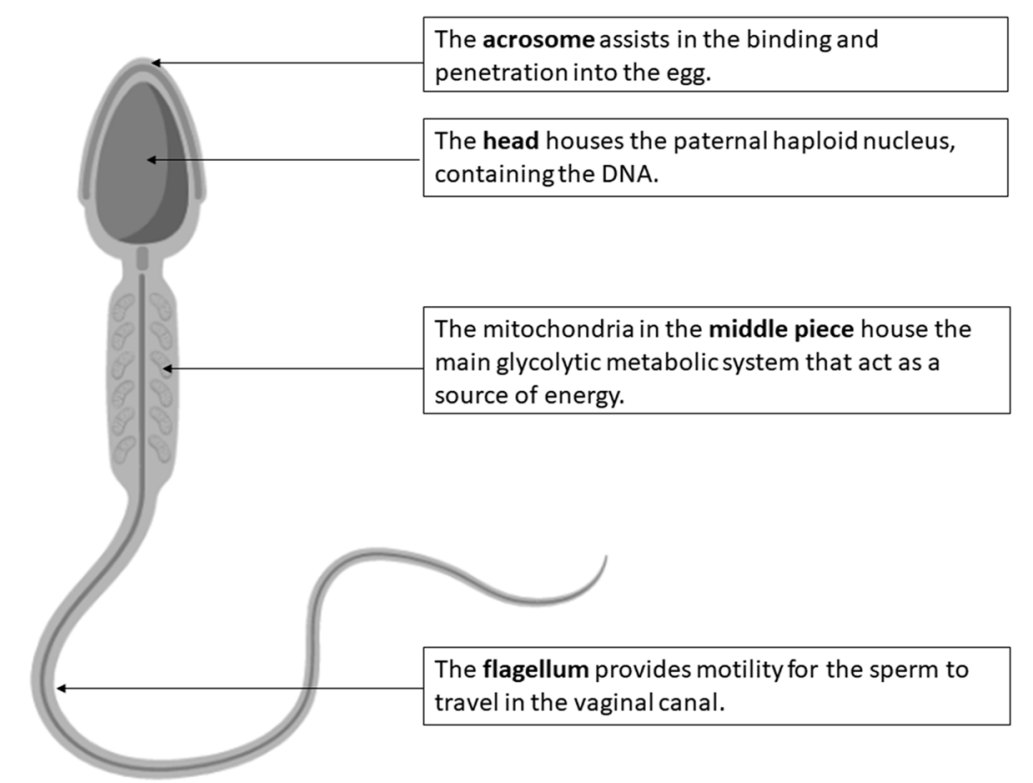

Fig. 2 Sperm cells essentially have four core elements: (1) a paternal haploid nucleus containing the DNA; (2) a mitochondrial and glycolytic metabolic system that act as a source of energy; (3) a motor (the flagellum) providing motility for the sperm to travel in the vaginal canal; and (4) a mechanism that assists in the binding and penetration into the egg (the acrosome)

The axoneme comprises nine outer doublet microtubules and central doublets $(9+2)$ associated with radial spokes and dynein arms. The dynein arms within the axoneme provide the motor apparatus for the movement of the sperm tail [22]. Proper formation of the axoneme during spermatogenesis is crucial in sperm motility. The structure of the sperm tail axoneme resembles that of motile cilia. Therefore, male infertility caused by malformations of the axonemal structure is often associated with primary ciliary dyskinesia (PCD). However, male infertility is not systematically investigated and often not recorded in cases of PCD [23].

An association between gene mutation and sperm motility and male infertility has been considered in several reviews. Mutations in more than 30 genes have been identified in cases of PCD including dynein arm preassembly genes. Defects in the axonemal outer dynein arms $(O D A)$ genes, dynein axonemal heavy chain 5 (DNAH5), and dynein axonemal intermediate chain 1 (DNAI1) leads to reduced sperm motility, even though sperm axoneme structure appears intact $[24,25]$. Mutations in inner dynein arms (IDA)-related coiled-coil domain-containing proteins $39(C C D C 39)$ and $40(C C D C 40)$ cause reduced sperm motility and absence of IDA [26]. Male infertility was also observed in cases showing defects in central pair-related genes. In humans, depletion of hydin causes PCD, and spermatozoa appear rigid and completely immotile [9]. It has been reported that several spermassociated antigen (Spag) genes (Spag6, Spag16, and
Spag17) in mice are important for central pair complex function. Infertility due to missing axonemal central pair and disorganized ODFs was caused by the total loss of Spag6 [10]. However, depletion of the SPAG16L isoform resulted only in sperm motility defects with intact axonemal structure [11]. A large number of people exhibit idiopathic asthenospermia. Understanding and screening for genetic anomalies that may hinder sperm motility and function are crucial in developing treatment strategies for such infertility cases.

\section{Role of calcium and bicarbonate ions on sperm motility} Soluble adenylate cyclase (sACs) are activated by $\mathrm{Ca}^{2+}$ and bicarbonate ions. They are the predominant ACs responsible for the generation of cAMP in spermatozoa and are involved in the increase in beat frequency in the spermatozoa. On the other hand, transmembrane ACs are not responsive to bicarbonate ions but are regulated by heterotrimeric G-proteins. Transmembrane ACs are involved in the basic mechanism for motility activation through cAMP-dependent protein phosphorylation and in progressive motility [27]. Calcium ions act as major secondary messengers and regulate the amount of cAMP in the cell [28]. The concentration of calcium is a crucial regulatory factor that affects capacitation, hyperactivation, and acrosome reaction. It has been observed that the flagellum beats asymmetrically when the intracellular $\mathrm{Ca}^{2+}$ concentration is low. The waveform becomes more asymmetric, and sperm becomes 
hyperactivated with a gradual increase in $\mathrm{Ca}^{2+}$. However, an excessively high amount of intracellular concentration of calcium reduces motility [29]. This occurs due to a decrease in protein phosphorylation caused by the increased concentration of $\mathrm{Ca}^{2+}$, which prevents substrate-kinase interactions [30]. Calmodulin is a $\mathrm{Ca}^{2+}$ receptor that orchestrates $\mathrm{Ca}^{2+}$-initiated signal transduction cascades leading to changes in cell function. It is a key axonemal $\mathrm{Ca}^{2+}$ sensor that mediates motility through direct interaction with protein kinases, phosphatases, and sAC [31]. The impact of the extracellular concentration of $\mathrm{Ca}^{2+}$ on motility has been well-debated. Several studies have reported that extracellular $\mathrm{Ca}^{2+}$ enhances sperm motility, whereas others have also reported that a high concentration of $\mathrm{Ca}^{2+}$ inhibits sperm motility. In conclusion, it is clear that the role of $\mathrm{Ca}^{2+}$ in sperm motility is paradoxical [28]. Bhoumik et al. have reported a biphasic role of extracellular calcium in the motility of caprine cauda epididymal spermatozoa. They observed that an optimum concentration of $10 \mu \mathrm{m}$ of $\mathrm{Ca}^{2+}$ significantly enhanced motility, whereas concentrations above this hindered motility [28]. This observation is particularly important because seminal plasma usually contains about $11 \mathrm{mM}$ of $\mathrm{Ca}^{2+}$ and about $0.24 \mathrm{mM}$ of free $\mathrm{Ca}^{2+}$; the remainder is complexed with citrate. Such high levels of free calcium in ejaculated semen until capacitation reaction may actually hinder sperm motility. With this study, Bhoumik et al. demonstrated the importance of maintaining optimum levels of calcium for enhanced motility [23 28]. Furthermore, along with the optimum extracellular $\mathrm{Ca}^{2+}$, bicarbonate ions are important anions that are transported into sperm during capacitation; they are important in the influx of $\mathrm{Ca}^{2+}$ ions [32]. Wennemuth et al. have reported that in vitro treatment with bicarbonate ion induces an influx of $\mathrm{Ca}^{2+}$, subsequently increasing flagellar beat frequency but decreasing flagellar beat asymmetry [33]. Therefore, it is clear that calcium plays a critical role in regulating sperm motility. Moreover, maintaining optimum concentrations of calcium is particularly important in ART.

\section{Reactive oxygen species and its role in sperm motility}

Reactive oxygen species (ROS) like superoxide anion, nitric oxide, and hydrogen peroxide play a crucial role in regulating sperm motility [34]. ROS are highly reactive and are known for their ability to initiate a cascade of chain reactions that lead to extensive cellular damage. Free radicals are usually by-products of different metabolic processes. An increase in ROS levels affects mitochondrial oxidative phosphorylation which further damages proteins and lipids. The plasma membrane in sperm contains lipids in the form of polyunsaturated fatty acids (PUFA). An increased amount of ROS results in lipid peroxidation thus affecting the integrity of the plasma membrane [7]. However, a small quantity of ROS is essential for normal sperm functioning. ROS can function as signalling molecules and are crucial in capacitation and acrosome reaction, as well as motility of mature sperm cells [35]. It is important that ROS is maintained at appropriate levels to ensure proper physiological function while preventing pathological damage to the sperm. Minute levels of superoxide ions trigger hyperactivation and capacitation [35,36]. Generally, ROS originate in the ejaculate by the spontaneous production of nicotinamide adenine dinucleotide phosphate oxidase system at the sperm plasma membrane level [37] and by the mitochondria in sperm $[15,38]$ as well as from leukocytes that infiltrate into semen [39]. Leukocytospermia, chronic inflammation, genitourinary tract infections, and various conditions such as varicocele, orchitis, cryptorchidism, and ageing lead to an increased amount of ROS, thus causing a decrease in sperm motility [40, 41]. Antioxidants like glutathione reductase and peroxidase in the epididymis and testes protect the lipid components on the sperm, thus preserving viability and motility. Superoxide dismutase, catalase, and glutathione peroxidase are some of the important antioxidant enzyme systems present in the semen $[7,35]$. Unhealthy lifestyles such as alcohol abuse, smoking, exposure to chemical pollutants, and electromagnetic radiation have increased instances of oxidative stress in the body. Sperm cells are highly susceptible to ROS-induced damage. ROS affects several critical processes like signal transductions in the sperm cell thereby contributing to impaired function. Therefore, it is critical to understand the mechanisms of how ROS and endogenous antioxidant systems affect sperm function.

\section{Role of $\mathrm{pH}$ on sperm motility}

All biophysiological events are dependent on $\mathrm{pH}$. Even a small alteration in the $\mathrm{pH}$ can either lead to a deviation in the function or even lead to the inhibition of a particular cell function [41]. Sperm cells encounter several changes in $\mathrm{pH}$ right from the maturation stage to the stage when they enter the uterotubal tract. Sperm cells encounter a $\mathrm{pH}$ of 7.2-7.4 in the mammalian seminiferous tubules, 6.5 in the caput epididymis, and 6.7-6.8 in the cauda epididymis. The $\mathrm{pH}$ of the semen during ejaculation becomes 7.2-7.4. On ejaculation into the vagina, the sperm encounters a $\mathrm{pH}$ of 4.5-7.5. Subsequently, the $\mathrm{pH}$ increases to $6.5-7.5$ in the cervix and 7-7.8 in the uterus and fallopian tube [42]. Being the only cell that performs its activity outside the male body, sperm cells are largely affected by the surrounding environment. Critical processes such as motility, viability, capacitation, and acrosome reaction are vastly influenced by 
$\mathrm{pH}$. Seminal plasma comprises a mixture of different secretions from the testes, epididymis, and other accessory sex glands. It also contains sugars, steroids, lipids, $\mathrm{HCO}_{3}{ }^{-1}$, organic acids, inorganic ions, amino acids, polyamines, nitrogenous bases, and proteins. Semen has a very high buffering capacity, much higher than most of the other body fluids [43]. The role of $\mathrm{pH}$ has been extensively studied in several bird, fish, and shellfish models. In a study involving sperm of turkey and quail, it was reported that sperm motility was restored in alkaline conditions [44]. The sperm of Anodontawoodiana Pacifica Houde showed enhanced motility at $\mathrm{pH} 8.5$, and there was a significant decline in the motility with the decrease in $\mathrm{pH}$ [45]. There are several mechanisms by which the $\mathrm{pH}$ in spermatozoa and its surrounding is regulated across different organisms. For instance, in fishes, the pituitary gland and gonadotropin stimulate the production of $17 \alpha$-hydroxyprogesterone in testicular somatic cells resulting in a marked increase in the production of $7 \alpha, 2 \beta$-dihydroxy-4-pregnen-3-one in spermatozoa; this increases the $\mathrm{pH}$ in the sperm duct, as well as the intrasperm cAMP, which initiates motility [46]. The mechanism that regulates $\mathrm{pH}$ in mammalian spermatozoa is more complex. $\mathrm{HCO}_{3}{ }^{-}$influx, voltage-gated proton channel (Hv1), and $\mathrm{Na}^{+} / \mathrm{H}^{+}$exchanger (NHE) are the three mechanisms by which $\mathrm{pH}$ is regulated in spermatozoa [42]. The $\mathrm{HCO}_{3}{ }^{-}$influx system involves the inward movement of $\mathrm{HCO}_{3}{ }^{-}$ions. Activation of soluble ACs results in the production of cAMP, thus promoting alkalinization and membrane hyperpolarization. $\mathrm{Na}^{+}$ plays a crucial role in this system as removal of $\mathrm{Na}^{+}$ions prevents alkalinization and hyperpolarization, indicating the presence of $\mathrm{Na}^{+} / \mathrm{HCO}_{3}{ }^{-}$co-transport mechanism in spermatozoa [47]. Carbonic anhydrase, an enzyme that catalyzes the reaction of $\mathrm{CO} 2$ and produces $\mathrm{HCO}^{-}$, plays an important role in the entrance of $\mathrm{HCO}_{3}{ }^{-}$[48]. Cystic fibrosis transmembrane is another regulator that plays a crucial role in the influx of $\mathrm{HCO}_{3}{ }^{-}$during capacitation [49]. The NHE is another mechanism that regulates the $\mathrm{pH}$ in spermatozoa. The NHE is present in the flagellum; a study noted that male mice that lacked NHEs were sterile and showed diminished sperm motility [50]. Another important $\mathrm{H}^{+}$transporter that is present across the membrane of the spermatozoa is the Hv1 channel or the voltage-gated proton channel. This membrane transporter is abundantly localized in the flagellum of the spermatozoa. A characteristic feature of this voltagegated proton channel is that it is activated at low intracellular $\mathrm{pH}$. Moreover, it conducts protons much more rapidly and efficiently and conducts them unidirectionally to the extracellular space, thus regulating the internal $\mathrm{pH}$ [42]. Therefore, it is clear that the $\mathrm{pH}$ regulates sperm motility by various mechanisms. $\mathrm{HCO}_{3}{ }^{-} / \mathrm{CO}_{2}$, inorganic ions, organic acids, sugars, lipids, steroids, amino acids, polyamines, nitrogenous bases, and proteins in the seminal plasma usually contribute to a buffering action. A disbalance in the $\mathrm{pH}$ of the seminal plasma contributes to impaired sperm motility and function. Therefore, understanding the effects of changes in seminal plasma $\mathrm{pH}$ may be useful in the treatment of impaired motility and infertility.

\section{Analysing sperm motility}

Sperm motility plays an important role in assisted reproductive technology. Semen analysis of infertile men is crucial as it reflects the overall functionality of sperm production by the testes and the patency of the genital tract, as well as the secretory activity of all accessory glands [51]. Ejaculate volume, sperm density, sperm motility, and sperm morphology are the typical parameters that are analysed during sperm analysis. The lower limits of normal as defined by the World Health Organization are as follows: semen volume $1.5 \mathrm{~mL}$, total sperm number 39 million/ejaculate, sperm concentration 15 $\mathrm{M} / \mathrm{mL}$, total motility $40 \%$, progressive motility $32 \%$, and morphologically normal forms $4 \%$. Hormonal evaluation is indicated in men with sperm concentration $<10 \mathrm{M} / \mathrm{mL}$ or with clinical evidence of an endocrinopathy. Genetic evaluation by karyotype and for Y chromosome microdeletions should be considered in men with sperm concentration $<10 \mathrm{M} / \mathrm{mL}$, and cystic fibrosis genetic testing should be performed in men with congenital absence of the vas deferens. Sperm motility is predominantly assessed using microscopic methods. Different types of movements such as progressive motility, non-progressive motility, or no motility are observed when evaluating motility [52].

More recently, methods such as the light scattering method, laser beam method, and multiple exposure photographic method have come into use for measuring sperm motility. Measuring horizontal velocity is a major drawback when using the aforementioned methods. In the recent past, a highly automated instrument has been developed to measure sperm motility. Computer-assisted semen analysis (CASA) is a sophisticated system that utilizes complex software and hardware, a high-resolution camera, and a microscope to analyse sperm concentration, morphology, and motility. Although most methods measure horizontal velocity, measuring vertical velocity is also important as only a smaller percentage of the spermatozoa exhibit vertical velocity. The movement of sperm on the vertical plane is important because healthy and motile sperm cells are expected to be more active and functional, enabling them to travel the entire female reproductive tract to fertilize the egg cell. Saha et al. have developed a method of measuring vertical sperm velocity 
using a novel computer-assisted method. In this method, an electromechanical system comprising a modified cuvette holder and a stepper motor was used. With this novel method, vertically moving sperm cells are detected at different heights using newly developed software. Since no method describes a way of measuring vertical velocity, this method highlights the importance of the vertical movement of sperm [53].

\section{Methods adopted in cases with inadequate sperm motility} Normal reproduction is an extremely complex process that involves an array of complicated steps. As mentioned earlier, the interaction between the sperm and the egg includes a complex set of reactions. The production of a sufficient number of sperm cells having adequate motility for it to travel through the vaginal canal into the fallopian tube and the ability to bring about fertilization is of utmost importance. These processes are highly regulated; any error at any stage drastically reduces the chances of conception. Assisted reproductive technologies (ARTs) are clinical methods that involve the in vitro handling of sperm, oocytes, and embryos for their use in reproduction [54]. ARTs came in as a ray of hope for individuals suffering from infertility, giving them an opportunity to conceive successfully.

The world's first in vitro fertilization (IVF) baby, Louise Brown, was born at Oldham General hospital on 25th July 1978. In 2010, Robert G Edwards was awarded the Nobel Prize for Physiology and Medicine for the development of IVF [55]. Since the development of the IVF method, there has been a steady increase in the use of ARTs over the last decades. Initially, it was presumed that male factor infertility was a contraindication to IVF because abnormal sperm are less likely to fertilize oocytes than normal sperm. However, subsequent analyses performed over a decade ago revealed that fertilization and subsequent live births were possible despite impaired sperm quality [56].

As of 2018, as many as eight million babies have been conceived by ART [55]. ARTs are routinely used in veterinarian clinical settings. Artificial insemination is the most routinely used method in breeding programs because of its simplicity and effectiveness [57]. Despite the huge success and the ever-growing research on ARTs, its efficiency still has a lot of potential to improve. The American and European societies of reproduction and fertility have reported the efficiencies of ICSI or IVF to be $37 \%$ and $25 \%$ of pregnancies and deliveries, respectively, per embryo transfer [58]. There are several reasons that contribute to low efficiencies such as suboptimal in vitro conditions, injuries associated with gametes and embryo manipulation, subjacent male and female factors, etc. Although ART has been the solution to problems associated with conception, it is still an expensive and invasive method. Therefore, there is a need to develop and discover novel methods to tackle infertility caused by impaired motility.

\section{The role of sperm surface molecules in sperm motility}

As mentioned earlier, immature sperm undergo several biochemical changes as they pass through different parts of the epididymis during maturation. During the epididymal transit, there is a marked increase in the intrasperm level of cAMP and $\mathrm{pH}$, thus suggesting that elevated intrasperm levels of cAMP and $\mathrm{pH}$ play an important role in the in vivo initiation of sperm forward progression. However, not much is known about the molecular basis of the initiation of flagellar motility while it is in the epididymis and its subsequent regulation. There are several cell surface molecules present on the sperm cell membrane. These molecules play a pivotal role in modulating cell-cell interactions, effector-receptor interactions, membrane permeability, membrane fluidity, transmembrane signalling, etc. Similarly, cell surface molecules present on sperm cells play a crucial role in processes like capacitation, acrosomal reaction, and fertilization [59-61]. A summary of these molecules is described in Fig. 3.

Lipids are important biomolecules that form the membrane bilayer permeability barrier of cells and organelles. Rana et al. have reported that there was a significant decrease in phospholipids (PL) and glycolipids (GL) of caprine sperm membrane during sperm maturation. Among the phospholipids, it was observed that the amounts of phosphatidylethanolamine showed the maximum decrease. However, an enhanced neutral lipid $(\mathrm{NL})$ fraction was noted during the transit from caput to cauda. Sterol and steryl esters, which are the major constituents of NL, were enhanced during maturation while other membrane-bound neutral lipids decreased. Since cholesterol $(\mathrm{CH})$ was the major component of the sterol fraction, the aforementioned changes led to appreciable enhancement in the cholesterol/phospholipid (CH/PL) ratio [62]. These findings suggest an important relationship between the lipid profile of the sperm plasma membrane and the maturation of sperm cells. However, the exact role of these changes in the lipid content on motility is still unknown. It is clear that cholesterol plays a crucial role in the capacitation reaction. During capacitation, a marked efflux of cholesterol results in an increase in membrane fluidity and permeability to bicarbonate and calcium ions which in turn affect motility.

Along with lipids, there are several regulatory protein complexes present on the surface of sperm cells. Majumdar et al. reported the presence of an ecto-cyclic AMPdependent protein kinase on the external surface of rat 


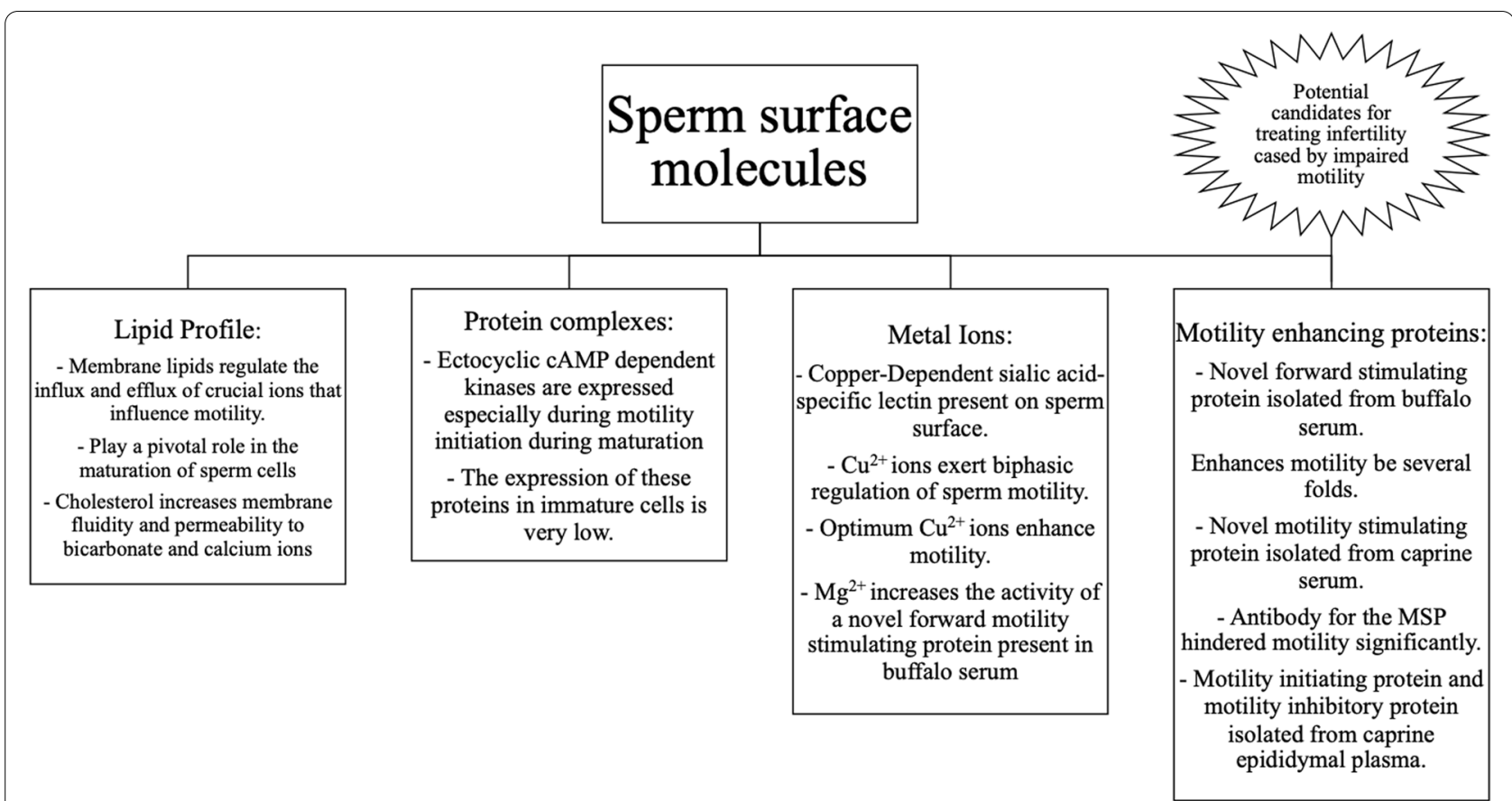

Fig. 3 Summary of the key sperm surface molecules that play an important role in regulating sperm motility. Several novel protein molecules have been found in the serum in buffalo and caprine systems; these molecules interact with their receptors, thus enhancing forward and vertical motility. These molecules can act as novel methods for treating infertility

spermatozoa [63]. Subsequently, several publications reported the localization of cAMP-dependent protein kinases and cell surface phosphoproteins on the surface of rats and human spermatozoa [64, 65]. Extracellular cAMP binds to the cAMP-binding protein thereby disassociating the catalytic subunit. The catalytic subunit, now active, brings about the phosphorylation of exogenous proteins in the presence of ATP. The amount of ecto-cAMP-dependent protein kinase is low in immature sperm cells. However, it appears specifically during motility initiation in the mature cauda sperm, indicating that it is maturation specific. Forward-motile sperm cells are enriched in both kinases. However, the exact role of the ecto-cAMP-dependent protein kinases in the induction and regulation of sperm motility is largely unknown $[65,66]$.

Along with ecto-cAMP-dependent protein kinases, ecto-cAMP-independent protein kinases on the outer surfaces of goat epididymal spermatozoa are known to phosphorylate serine and threonine residues of multiple endogenous proteins localized on the sperm outer surface. The intact sperm-bound ectoenzyme is also capable of phosphorylating exogenous proteins such as casein, phosvitin, histone, and protamine [67]. It has been demonstrated that the incorporation of major physiological substrate (MPS) proteins of ecto-cAMP-independent kinases increases motility and forward motility.
Moreover, at maximal MPS incorporation, the increments in motility and forward motility were also maximal [68]. Therefore, it can be conclusively said that MPS, the sperm membrane-bound phosphoprotein, serves as an activator of sperm forward motility.

Another interesting observation was noted by Roy et al., where they observed that the incorporation of $\mathrm{Cu}^{2+}$ enhanced forward motility of caprine spermatozoa. However, increasing the $\mathrm{Cu}^{2+}$ concentration beyond $5 \mu \mathrm{M}$ reduced forward motility. This is a clear indication that $\mathrm{Cu}^{2+}$ exerts a biphasic regulation on sperm motility. Moreover, increasing the concentration of $\mathrm{Cu}^{2+}$ to beyond $100 \mu \mathrm{M}$ led to sperm head-to-head agglutination [69]. Eventually, Roy et al. reported the presence of a novel copper-dependent sialic acid-specific lectin on the external surface of sperm cells that binds with its specific receptor of neighbouring cells thereby causing sperm-sperm agglutination. It was also noted that immature sperm cells do not undergo agglutination in the presence of copper, thus indicating that this unique copper-dependent lectin/ receptor is acquired during epidydimal maturation. It has been proposed that the copper ion modulates cell surface lectin-sugar interactions. However, the mechanisms by which it affects motility need to be studied in detail [70]

Acott et al. demonstrated the induction of motility in immotile sperm cells after incubating the immotile cells 
with epididymal or seminal plasma [71]. This suggested the presence of factors in the epididymal or seminal plasma that have the ability to modulate sperm motility extracellularly.

Mandal et al. demonstrated for the first time the presence and the effect of a novel forward motility-promoting protein extracted from buffalo serum. This forward motility-stimulating factor (FMSF) is a $66-\mathrm{kDa}$ heatstable glycoprotein. It is also an $\mathrm{Mg}^{2+}$-dependent monomeric protein, and both its protein and sugar parts of the protein are essential for its motility-promoting potential. Further studies revealed that this forward motility-stimulating protein through receptor/G-protein activation promotes the transmembrane AC activity in a dosedependent manner to enhance intracellular cAMP and forward motility. Protein kinase A and tyrosine kinase are key players in regulating motility under the influence of forward-stimulating protein. The FMSF initiates a novel signalling cascade by stimulating tmAC activity which supplements intracellular cAMP and downstream crosstalk of phosphokinases, thus enhancing forward motility in mature spermatozoa. The FMSF binds to specific receptors that are present on the external cell surface, which leads to the activation of adenylate cyclase and consequently enhances intra-sperm cAMP level that triggers the flagellar movement through a series of cascade molecules including protein kinase $\mathrm{A}$ and tyrosine kinase $[72,73]$.

Saha et al. 2013 reported a novel motility stimulating protein (MSP) isolated and purified from caprine blood serum. This novel $66-\mathrm{kDa}$ heat-stable protein-enhanced sperm horizontal forward motility as well as vertical velocity at a concentration of $0.9 \mu \mathrm{M}$. Furthermore, it was noted that these proteins were distributed on the surface of the sperm cells. It was also found that this motility stimulating protein showed cAMP-independent activity and that there must be alternative pathways through which motility-stimulating activity is mediated, which still needs to be identified [74].

A motility-initiating protein (MIP) and a motilityinhibiting factor (MIF) were then identified from caprine epididymal plasma $[75,76]$. The addition of MIP induced forward motility, and there was a significant increase in the number of motile sperm cells. Furthermore, the addition of a rabbit polyclonal antibody raised against purified sperm motility-inhibiting factor (MIF-II) enhanced sperm motility by $75 \%$ compared with the control. A $40 \%$ increase in vertical velocity of MIF-II antibody-treated spermatozoa was observed as compared to the control serum. MIF-II antibody also enhanced the motility of immature caput spermatozoa under in vitro initiation media [77].
These novel motility-promoting proteins are promising candidates in enhancing motility in sperm samples that display poor motility traits. These proteins are physiological activators of sperm motility, and they can be used in biomedical applications in human infertility clinics and infertility management, as well as animal breeding and conservation centres. Currently, treatment of male infertility involves invasive procedures like surgery, hormonal treatment, ART, etc. which are not only expensive but also may have detrimental effects on the quality of life.

\section{Conclusion}

Human infertility is a social stigma in many cultures and causes mental stress and trauma, and it affects a large number of people globally. Studies show that about $40-50 \%$ of the infertility cases are attributed to male factor fertility, and as many as $2 \%$ of all men exhibit suboptimal sperm parameters. Currently, there are limited treatment strategies available for tackling infertility. There are several sophisticated ART methods (e.g., IVF and ICSI) that are routinely employed to tackle and treat individuals affected by infertility.

For several years, managing and treating male factor infertility was mostly based on "experience" and not "evidence". Choosing the correct technique for tackling infertility is an important issue. This usually depends on the sperm parameters. However, most of these technologies have several disadvantages. They are invasive and expensive; moreover, their success rate is also very low. Most ARTs utilize hormonal treatments that have various sideeffects on the individual and affect the quality of life. This review has described several molecular mechanisms that play a critical role in regulating sperm motility. Concentrations of calcium, hydrogen ions, $\mathrm{pH}$, are some of the factors that affect sperm motility. An optimum concentration of extra- and intra-cellular $\mathrm{Ca}^{2+}, \mathrm{HCO}_{3}{ }^{-}$, and $\mathrm{ROS}$, along with the proper maintenance of $\mathrm{pH}$ is critical in maintaining proper sperm function. Moreover, along with the various biochemical mechanisms and the optimum microenvironments that are essential in regulating cellular functions, cell surface molecules also play a critical role in regulating various cellular processes such as transmembrane signalling, cell-cell interactions, and effector-receptor interactions. These molecular mechanisms can be exploited by using several key surface molecules to tackle impaired motility. Therefore, identifying sperm surface molecules and understanding their roles in sperm physiology are important as these will help in treating various anomalies associated with sperm motility and behaviour. These motility-promoting proteins have the potential for improving cattle and poultry breeding and conservation of endangered species. Understanding 
sperm motility and the specific motility-promoting molecules may also be useful in human infertility clinics as a solution to problems associated with human infertility.

Utilizing motility-inducing proteins and other sperm surface proteins will negate hormonal treatments that may affect the quality of life of an individual. Understanding the role of spermatozoa and seminal plasma proteomes, along with surface proteins and molecules, will open up new avenues in understanding infertility and tackling it effectively.

\begin{abstract}
Abbreviations
$\mathrm{HCO}_{3}{ }^{-}$: Bicarbonate ions; $\mathrm{Ca}^{2+}$ : Calcium ions; cAMP: Cyclic adenosine monophosphate; ICSI: Intracytoplasmic sperm injection; PKA: Protein kinase A; PCD: Primary ciliary dyskinesia; ODA: Outer dynein arms; DNAH5: Dynein axonemal heavy chain 5; DNA/1 : Dynein axonemal intermediate chain 1; IDA: Inner dynein arms; CCDC: Coiled-coil domain-containing proteins; Spag: Sperm-associated antigen; ACs: Adenylate cyclase; ROS: Reactive oxygen species; PUFA: Polyunsaturated fatty acids; $\mathrm{NHE:} \mathrm{Na}^{+} / \mathrm{H}^{+}$exchanger; CASA: Computer-assisted semen analysis; ARTs: Assisted reproductive technologies; IVF: In vitro fertilization; PL: Phospholipids; GL: Glycolipids; NL: Neutral lipid; CH: Cholesterol; MPS: Major physiological substrate; FMSF: Forward motility-stimulating factor; MSP: Motility-stimulating protein; MIP: Motility-initiating protein; MIF: Motility-inhibiting factor.
\end{abstract}

\section{Acknowledgements}

The authors would like to thank the Science and Engineering Research Board (SERB).

\section{Authors' contributions}

All authors contributed equally to this paper. Both SC and SS conceived and designed the theme of the review. SC wrote the paper under the guidance of SS. The authors read and approved the final manuscript.

\section{Funding}

Science and Engineering Research Board-Start-up Research Grant (SERB-SRG), Project No. SRG/2019/000501

\section{Availability of data and materials}

Data sharing is not applicable to this article as no datasets were generated or analysed during the current study.

\section{Declarations}

Ethics approval and consent to participate

Not applicable

\section{Consent for publication}

Not applicable

\section{Competing interests}

The authors declare that they have no competing interests.

Received: 26 August 2021 Accepted: 10 January 2022

Published online: 03 February 2022

\section{References}

1. Kumar N, Singh AK (2015) Trends of male factor infertility, an important cause of infertility: a review of literature. J Hum Reprod Sci 8:191-196. https://doi.org/10.4103/0974-1208.170370 PMID 26752853

2. Anawalt BD (2013) Approach to male infertility and induction of spermatogenesis. J Clin Endocrinol Metab 98:3532-3542. https://doi.org/10. 1210/jc.2012-2400 PMID 24014811
3. Ickowicz D, Finkelstein M, Breitbart H (2012) Mechanism of sperm capacitation and the acrosome reaction: role of protein kinases. Asian J Androl 14:816-821. https://doi.org/10.1038/aja.2012.81 PMID 23001443

4. Zaneveld LJD, De Jonge CJD, Anderson RA, Mack SR (1991) Human sperm capacitation and the acrosome reaction. Hum Reprod 6:1265-1274. https://doi.org/10.1093/oxfordjournals.humrep.a137524 PMID 1752929

5. Breitbart H, Finkelstein M (2015) Regulation of sperm capacitation and the acrosome reaction by PIP 2 and actin modulation. Asian J Androl 17:597-600. https://doi.org/10.4103/1008-682X.154305 PMID 25966627

6. Ortega C, Verheyen G, Raick D, Camus M, Devroey P, Tournaye H (2011) Absolute asthenozoospermia and ICSI: what are the options? Hum Reprod Update 17:684-692. https://doi.org/10.1093/humupd/dmr018 PMID 21816768

7. Tafuri S, Ciani F, lorio EL, Esposito L, Cocchia N (2015) Reactive oxygen species (ROS) and male fertility. N Discov Embryol. https://doi.org/10. 5772/60632

8. Blumer CG, Fariello RM, Restelli AE, Spaine DM, Bertolla RP, Cedenho AP (2008) Sperm nuclear DNA fragmentation and mitochondrial activity in men with varicocele. Fertil Steril 90:1716-1722. https://doi.org/10.1016/j. fertnstert.2007.09.007

9. Olbrich H, Schmidts M, Werner C, Onoufriadis A, Loges NT, Raidt J, Banki NF, Shoemark A, Burgoyne T, AI Turki S, Hurles ME, UK10K Consortium, Köhler G, Schroeder J, Nürnberg G, Nürnberg P, Chung EM, Reinhardt R, Marthin JK, Nielsen KG, Mitchison HM, Omran H (2012) Recessive HYDIN mutations cause primary ciliary dyskinesia without randomization of leftright body asymmetry. Am J Hum Genet 91:672-684. https://doi.org/10. 1016/j.ajhg.2012.08.016 (PMID 23022101)

10. Sapiro R, Kostetskii I, Olds-Clarke P, Gerton GL, Radice GL, Strauss JF 3rd. (2012) Male infertility, impaired sperm motility, and hydrocephalus in mice deficient in sperm-associated antigen 6. Mol Cell Biol 22:6298-6305. https://doi.org/10.1128/MCB.22.17.6298-6305.2002 PMID 12167721

11. Zhang Z, Kostetskii I, Tang W, Haig-Ladewig L, Sapiro R, Wei Z, Patel AM, Bennett J, Gerton GL, Moss SB, Radice GL, Strauss JF 3rd (2006) Deficiency of SPAG16L causes male infertility associated with impaired sperm motility. Biol Reprod 74:751-759

12. Dcunha R, Hussein RS, Ananda H, Kumari S, Adiga SK, Kannan N, Zhao Y, Kalthur G (2020) Current insights and latest updates in sperm motility and associated applications in assisted reproduction. Reprod Sci. https:// doi.org/10.1007/s43032-020-00408-y PMID 33289064

13. Mohammadi S, Kianmehr M, Mohammadi M, Fahimian Z, Karimimanesh E, Farazifar M et al (2019) Correlation between expression of CatSper1,2 and sperm parameters in the gamma irradiated adult mouse testis. Int J Radiat Biol 95(6):691-696. https://doi.org/10.1080/09553002.2019.15523 72

14. Kanter M, Aktas C, Erboga M (2013) Heat stress decreases testicular germ cell proliferation and increases apoptosis in short term: an immunohistochemical and ultrastructural study. Toxicol Ind Health 29(2):99-113. https://doi.org/10.1177/0748233711425082

15. Aitken RJ, West K, Buckingham D (1994) Leukocytic infiltration into the human ejaculate and its association with semen quality, oxidative stress, and sperm function. J Androl 15:343-352 PMID 7982803

16. Cornwall GA, von Horsten HH (2007) Sperm maturation in the epididymis In: Carrell DT (ed) The genetics of male infertility. Humana Press. https:// doi.org/10.1007/978-1-59745-176-5_13

17. van Der Horst GVD, Seier JV, Spinks AC, Hendricks S (1999) The maturation of sperm motility in the epididymis and vas deferens of the vervet monkey, Cercopithecus aethiops. Int J Androl 22:197-207. https://doi.org/10. 1046/j.1365-2605.1999.00171.x PMID 10367241

18. Turner TT In: Hinton BT, Turner TT (eds) (2003) Which aspects of epididymal function require increased emphasis in future research? Charlottesville: The Third International Conference on the Epididymis, Van Doren Company 277-282. https://books.google.co.in/books/about/The_Third_ International_Conference_on_th.html?id=bM8nngEACAAJ\&redir_esc=y

19. Buffone MG, Wertheimer EV, Visconti PE, Krapf D (2014) Central role of soluble adenylyl cyclase and CAMP in sperm physiology. Biochim Biophys Acta 1842:2610-2620. https://doi.org/10.1016/j.bbadis.2014.07.013 PMID 25066614

20. Rahman MS, Kwon WS, Pang MG (2014) Calcium influx and male fertility in the context of the sperm proteome: an update. Biomed Res Int 2014:841615. https://doi.org/10.1155/2014/841615 PMID 24877140 
21. Wallach E, Amelar RD, Dubin L, Schoenfeld C (1980) Sperm motility. Fertil Steril 34:197-215. https://doi.org/10.1016/S0015-0282(16)44949-6

22. Kobayashi D, Takeda H (2012) Ciliary motility: the components and cytoplasmic preassembly mechanisms of the axonemal dyneins. Differentiation 83:S23-S29. https://doi.org/10.1016/j.diff.2011.11.009 PMID 22154137

23. Lehti MS, Sironen A (2017) Formation and function of sperm tail structures in association with sperm motility defects. Biol Reprod 97:522-536. https://doi.org/10.1093/biolre/iox096 PMID 29024992

24. Fliegauf M, Olbrich H, Horvath J, Wildhaber JH, Zariwala MA, Kennedy M, Knowles MR, Omran H (2005) Mislocalization of DNAH5 and DNAH9 in respiratory cells from patients with primary ciliary dyskinesia. Am J Respir Crit Care Med 171:1343-1349. https://doi.org/10.1164/rccm.2004111583OC PMID 15750039

25. Zuccarello D, Ferlin A, Cazzadore C, Pepe A, Garolla A, Moretti A, Cordeschi G, Francavilla S, Foresta C (2008) Mutations in dynein genes in patients affected by isolated non-syndromic asthenozoospermia. Hum Reprod v23:1957-1962. https://doi.org/10.1093/humrep/den193 PMID 18492703

26. Blanchon S, Legendre M, Copin B, Duquesnoy P, Montantin G, Kott E, Dastot F, Jeanson L, Cachanado M, Rousseau A, Papon JF, Beydon N, Brouard J, Crestani B, Deschildre A, Désir J, Dollfus H, Leheup B, Tamalet A, Thumerelle C, Vojtek AM, Escalier D, Coste A, de Blic J, Clément A, Escudier E, Amselem S (2012) Delineation of CCDC39/CCDC40 mutation spectrum and associated phenotypes in primary ciliary dyskinesia. J Med Genet 49:410-416. https://doi.org/10.1136/jmedgenet-2012-100867 PMID 22693285

27. Steegborn C (2014) Structure, mechanism, and regulation of soluble adenylyl cyclases - similarities and differences to transmembrane adeny|yl cyclases. Biochim Biophys Acta 1842:2535-2547. https://doi.org/10. 1016/j.bbadis.2014.08.012 PMID 25193033

28. Bhoumik A, Saha S, Majumder GC, Dungdung SR (2014) Optimum calcium concentration: a crucial factor in regulating sperm motility in vitro. Cell Biochem Biophys 70:1177-1183. https://doi.org/10.1007/s12013-0140038-x PMID 24880438

29. Suarez SS, Varosi SM, Dai X (1993) Intracellular calcium increases with hyperactivation in intact, moving hamster sperm and oscillates with the flagellar beat cycle. Proc Natl Acad Sci U S A 90:4660-4664. https://doi. org/10.1073/pnas.90.10.4660 PMID 8506314

30. Tash JS, Means AR (1982) Regulation of protein phosphorylation and motility of sperm by cyclic adenosine monophosphate and calcium. Biol Reprod 26:745-763. https://doi.org/10.1095/biolreprod26.4.745 PMID 6282354

31. Pereira R, Sá R, Barros A, Sousa M (2017) Major regulatory mechanisms involved in sperm motility. Asian J Androl 19:5-14. https://doi.org/10. 4103/1008-682X.167716 PMID 26680031

32. Luconi M, Porazzi I, Ferruzzi P, Marchiani S, Forti G, Baldi E (2005) Tyrosine phosphorylation of the a kinase anchoring protein 3 (AKAP3) and soluble adenylate cyclase are involved in the increase of human sperm motility by bicarbonate 1. Biol Reprod 72:22-32. https://doi.org/10.1095/biolr eprod.104.032490

33. Wennemuth G, Carlson AE, Harper AJ, Babcock DF (2003) Bicarbonate actions on flagellar and $\mathrm{Ca}_{2}{ }^{+}$-channel responses: initial events in sperm activation. Development 130:1317-1326. https://doi.org/10.1242/dev. 00353

34. Agarwal A, Saleh RA, Bedaiwy MA (2003) Role of reactive oxygen species in the pathophysiology of human reproduction. Fertil Steril 79:829-843. https://doi.org/10.1016/s0015-0282(02)04948-8

35. Saha S, Dungdung S, Majumder G (2014) Determination of the antioxidant potential of goat sperm cells. Oxid Antioxid Med Sci 3:195. https:// doi.org/10.5455/oams.290914.or.075

36. De Lamirande E, Gagnon C (1995) Impact of reactive oxygen species on spermatozoa: a balancing act between beneficial and detrimental effects Hum Reprod 10:S15-S21. https://doi.org/10.1093/humrep/10.suppl_1.15 PMID 8592032

37. Aitken RJ, Fisher HM, Fulton N, Gomez E, Knox W, Lewis B, Irvine S (1997) Reactive oxygen species generation by human spermatozoa is induced by exogenous NADPH and inhibited by the flavoprotein inhibitors diphenylene iodonium and quinacrine. Mol Reprod Dev 47:468-482 https://doi.org/10.1002/(sici)1098-2795(199708)47:4\%3c468::aidmrd14\%3e3.0.co;2-s, PMID 9211432
38. Amaral A, Lourenço B, Marques M, Ramalho-Santos J (2013) Mitochondria functionality and sperm quality. Reproduction 146:R163-R174. https:// doi.org/10.1530/REP-13-0178 PMID 23901129

39. Ochsendorf FR (1999) Infections in the male genital tract and reactive oxygen species. Hum Reprod Update 5:399-420. https://doi.org/10.1093/ humupd/5.5.399 PMID 10582780

40. Eskenazi B, Kidd SA, Marks AR, Sloter E, Block G, Wyrobek AJ (2005) Antioxidant intake is associated with semen quality in healthy men. Hum Reprod 20:1006-1012. https://doi.org/10.1093/humrep/deh725 PMID 15665024

41. Casey JR, Grinstein S, Orlowski J (2010) Sensors and regulators of intracellular pH. Nat Rev Mol Cell Biol 11:50-61. https://doi.org/10.1038/nrm2820 PMID 19997129

42. Mishra AK, Kumar A, Swain DK, Yadav S, Nigam R (2018) Insights into PH regulatory mechanisms in mediating spermatozoa functions. Vet World 11:852-858. https://doi.org/10.14202/vetworld.2018.852-858 PMID 30034181

43. Wolters-Everhardt E, Dony JMJ, Lemmens WAJG, Doesburg WH, De Pont JJ (1986) Buffering capacity of human semen. Fertil Steril 46:1 14-119. https://doi.org/10.1016/S0015-0282(16)49468-9 (PMID 3720968)

44. Holm L, Wishart GJ (1998) The effect of pH on the motility of spermatozoa from chicken, Turkey and quail. Anim Reprod Sci 54:45-54. https:// doi.org/10.1016/S0378-4320(98)00142-0 (PMID 9877064)

45. Huang R, Sun LP (2001) Effects of different $\mathrm{pH}$ conditions and inorganic positive ions on the sperm motility of Anodonta woodiana Pacifica Houde. Journal Fuzhou teacher's college Press 20:5

46. Nagahama Y (1994) Endocrine regulation of gametogenesis in fish. Int J Dev Biol 38:217-229 PMID 7981031

47. Chen WY, Xu WM, Chen ZH, Ni Y, Yuan YY, Zhou SC, Zhou WW, Tsang LL, Chung YW, Höglund P, Chan HC, Shi QX (2009) $\mathrm{Cl}^{-}$is required for $\mathrm{HCO}^{-}$ entry necessary for sperm capacitation in Guinea pig: involvement of $\mathrm{a} \mathrm{cl}^{-} / \mathrm{HCO}^{-}$exchanger (SLC26A3) and CFT. Biol Reprod 80:115-123. https://doi.org/10.1095/biolreprod.108.068528 PMID 18784352

48. Wandernoth PM, Mannowetz N, Szczyrba J, Grannemann L, Wolf A, Becker HM, Sly WS, Wennemuth G (2015) Normal fertility requires the expression of carbonic anhydrases II and IV in sperm. J Biol Chem 290:29202-29216. https://doi.org/10.1074/jbc.M1 15.698597 PMID 26487715

49. Puga Molina LC, Pinto NA, Torres Rodríguez P, Romarowski A, Vicens Sanchez A, Visconti PE, Darszon A, Treviño CL, Buffone MG (2017) Essential role of CFTR in PKA-dependent phosphorylation, alkalinization, and hyperpolarization during human sperm capacitation. J Cell Physiol 232:1404-1414. https://doi.org/10.1002/jcp.25634 PMID 27714810

50. Wang D, Hu J, Bobulescu IA, Quill TA, McLeroy P, Moe OW, Garbers DL (2007) A sperm-specific $\mathrm{Na}^{+} / \mathrm{H}^{+}$exchanger (sNHE) is critical for expression and in vivo bicarbonate regulation of the soluble adenylyl cyclase (sAC). Proc Natl Acad Sci U S A 104:9325-9330. https://doi.org/10.1073/ pnas.0611296104

51. Centola GM (2014) Semen assessment. Urol Clin North Am 41:163-167. https://doi.org/10.1016/j.ucl.2013.08.007

52. Stephens SM, Arnett DM, Meacham RB (2013) The use of in vitro fertilization in the management of male infertility: what the urologist needs to know. Rev Urol 15:154-160

53. Saha S, Paul D, Mukherjee A, Banerjee S, Majumder GC (2007) A computerized spectrophotometric instrumental system to determine the "vertical velocity" of sperm cells: a novel concept. Cytometry A 71:308-316. https://doi.org/10.1002/cyto.a.20382

54. Oseguera-López I, Ruiz-Díaz S, Ramos-Ibeas P, Pérez-Cerezales S (2019) Novel techniques of sperm selection for improving IVF and ICSI outcomes. Front Cell Dev Biol 7:298. https://doi.org/10.3389/fcell.2019.00298

55. Goisis A, Håberg SE, Hanevik HI, Magnus MC, Kravdal Ø (2020) The demographics of assisted reproductive technology births in a Nordic country. Hum Reprod 35:1441-1450. https://doi.org/10.1093/humrep/deaa055

56. Schlegel PN, Girardi SK (1997) In vitro fertilization for male factor infertility. J Clin Endocrinol Metab 82:709-716. https://doi.org/10.1210/jcem.82.3. 3785 PMID 9062469

57. Hansen PJ (2013) Current and future assisted reproductive technologies for mammalian farm animals. Current and future reproductive technologies and world food production. Adv Exp Med Biol:1-22. https://doi.org/ 10.1007/978-1-4614-8887-3_1 
58. De Geyter C, Calhaz-Jorge C, Kupka MS, Wyns C, Mocanu E, Motrenko T, Scaravelli G, Smeenk J, Vidakovic S, Goossens V, European IVF-monitoring Consortium (EIM) for the European Society of Human Reproduction and Embryology (ESHRE) (2018) ART in Europe, 2014: results generated from European registries by ESHRE: the European IVF-monitoring consortium (EIM) for the European Society of Human Reproduction and Embryology (ESHRE). Hum Reprod 33:1586-1601. https://doi.org/10.1093/humrep/ dey242 PMID 30032255

59. Majumder GC, Dey CS, Haldar S, Barua M (1990) Biochemical parameters of initiation and regulation of sperm motility. Arch Androl 24:287-303. https://doi.org/10.3109/01485019008987585

60. Yoshida M, Kawano N, Yoshida K (2008) Control of sperm motility and fertility: diverse factors and common mechanisms. Cell Mol Life Sci 65:3446-3457. https://doi.org/10.1007/s00018-008-8230-z PMID 18622578

61. Majumder GC, Saha S, Das K et al (2015) Chapter 8, role of sperm surface molecules in motility regulation. In: Mammalian endocrinology and male reproductive biology, 1st edn. CRC Press, India, pp 197-244

62. Rana APS, Majumder GC, Misra S, Ghosh A (1991) Lipid changes of goat sperm plasma membrane during epididymal maturation. Biochim Biophys Acta 1061:185-196. https://doi.org/10.1016/0005-2736(91)90284-F

63. Majumder GC (1981) Enzymic characteristics of an ecto-cyclic AMPdependent protein kinase in rat epididymal spermatozoa. Biochem J 195:111-117. https://doi.org/10.1042/bj1950111

64. Atherton RW, Khatoon S, Schoff PK, Haley BE (1985) A study of rat epididymal sperm adenosine 3',5'-monophosphate-dependent protein kinases: maturation differences and cellular location. Biol Reprod 32:155-171. https://doi.org/10.1095/biolreprod32.1.155

65. Pariset CC, Roussel C, Weinman SJ, Demaille JG (1983) Calmodulin intracelluar concentration and CAMP-dependent protein kinase activity in human sperm samples in relation to sperm motphlogy and motlity. Gamete Res 8:171-182. https://doi.org/10.1002/mrd.1120080206

66. Dey CS, Majumder GC (1990b) Type I and II CAMP-dependent ecto-protein kinases in goat epididymal spermatozoa and their enriched activities in forward-motile spermatozoa. Biochem Cell Biol 68:459-470. https:// doi.org/10.1139/090-065

67. Haldar S, Majumder GC (1986) Phosphorylation of external cell-surface proteins by an endogenous ecto-protein kinase of goat epididymal intact spermatozoa. Biochim Biophys Acta 887:291-303. https://doi.org/10. 1016/0167-4889(86)90157-6 PMID 3524694

68. Maiti A, Mishra KP, Majumder GC (2008) Role of the major ecto-phosphoprotein in sperm flagellar motility using a cell electroporation method. Mol Reprod Dev 75:1185-1195. https://doi.org/10.1002/mrd.20854

69. Roy D, Dey S, Majumder GC, Bhattacharyya D (2014a) Copper: a biphasic regulator of caprine sperm forward progression. Syst Biol Reprod Med 60:52-57. https://doi.org/10.3109/19396368.2013.848243

70. Roy D, Dey S, Majumder GC, Bhattacharyya D (2014) Occurrence of novel $\mathrm{Cu} 2^{+}$-dependent sialic acid-specific lectin, on the outer surface of mature caprine spermatozoa. Glycoconj J 31:281-288. https://doi.org/10. 1007/s10719-014-9524-z (PMID 24748468)

71. Acott TS, Hoskins DD (1978) Bovine sperm forward motility protein. Partial purification and characterization. J Biol Chem 253:6744-6750. https://doi. org/10.1016/S0021-9258(17)37981-4

72. Mandal M, Saha S, Ghosh AK, Majumder GC (2006) Identification and characterization of a sperm motility promoting glycoprotein from buffalo blood serum. J Cell Physiol 209:353-362. https://doi.org/10.1002/jcp. 20734

73. Dey S, Roy D, Majumder GC, Bhattacharyya D (2014) Extracellular regulation of sperm transmembrane adenylyl cyclase by a forward motility stimulating protein. PLoS One 9:e1 10669. https://doi.org/10.1371/journal. pone.0110669

74. Saha S, Das S, Bhoumik A, Ghosh P, Majumder GC, Dungdung SR (2013) Identification of a novel sperm motility-stimulating protein from caprine serum: its characterization and functional significance. Fertil Steril 100:269-279.e1. https://doi.org/10.1016/j.fertnstert.2013.03.012

75. Jaiswal BS, Das K, Saha S, Dungdung SR, Majumder GC (2010) Purification and characterization of a motility initiating protein from caprine epididymal plasma. J Cell Physiol 222:254-263. https://doi.org/10.1002/jcp.21947

76. Das S, Saha S, Majumder GC, Dungdung SR (2010) Purification and characterization of a sperm motility inhibiting factor from caprine epididymal plasma. PLoS One 5:e12039. https://doi.org/10.1371/journal.pone.00120 39

77. Dungdung SR, Bhoumik A, Saha S, Ghosh P, Das K, Mukherjee S, Nath D, Chakrabarty J, Kundu C, Jaiswal BS, Mandal M, Maiti A et al (2016) Sperm motility regulatory proteins: a tool to enhance sperm quality. Insights Anim Reprod. https://doi.org/10.5772/62470

\section{Publisher's Note}

Springer Nature remains neutral with regard to jurisdictional claims in published maps and institutional affiliations.

\section{Submit your manuscript to a SpringerOpen ${ }^{\circ}$ journal and benefit from:}

- Convenient online submission

- Rigorous peer review

- Open access: articles freely available online

- High visibility within the field

- Retaining the copyright to your article

Submit your next manuscript at $\mathbf{s p r i n g e r o p e n . c o m ~}$ 